\title{
EXPERIENCE ON A LARGE COMPOSITE SUPERCONDUCTING WIRE PRODUCTION RUN
}

\author{
T.A.deWinter \\ Magnetic Corporation of America, Waltham, Massachusetts 02154 \\ R.H.Remsbottom* and B.P.Strauss \\ Fermi National Accelerator Lab**, Batavia, Illinois 60510
}

\begin{abstract}
An order for approximately 15 million feet of $.027^{\prime \prime}$ diameter $\mathrm{NbTi}$ composite superconductor is nearing completion. The costs of fabrication for this conductor have become less than the costs of the components furnished to the manufacturer by Fermi National Accelerator Laboratory. Production and quality control procedures which have helped to reach these low cost levels are discussed. The performance of the conductor is compared with the specifications.
\end{abstract}

\section{INTRODUCTION}

The following presents a description of the production process for .027" diameter multifilamentary NbTi composite superconductor produced in large quantities starting with nominal 10" diameter extrusions. The original specifications for the conductor as formulated by Fermilab are listed in detail. The characteristics of the production conductor conforming to Fermilab's specifications are also described in detail. Processing operations for the entire production run are described and some of the economies are discussed.

\footnotetext{
*Also at University of Wisconsin, Madison

**Operated by Universities Research Association, Inc. for the United States Energy Research and Development Administration
} 


\section{FERMILAB SPECIFICATION}

Fermilab, in its original request for proposals as well as in contracts awarded for superconducting wire to be used in the Energy Doubler Program, has specified several parameters for the conductor to be fabricated using materials furnished by Fermilab. Specified were the following:

\section{$\mathrm{Cu} / \mathrm{SC}$ Ratio:}

Current Density:

Diameter:

Coating:

Filament Diameter:

Twist Pitch:

Min. Acceptable Length:

Percentage of Lengths

Acceptable between 1000 '

and $2000^{\prime}$ in length:
At least 1.8:1

Minimum $1.85 \times 10^{5} \mathrm{~A} / \mathrm{cm}^{2}$

at $5 \mathrm{~T}$ and $4.2 \mathrm{~K}$

$.027^{\prime \prime}$

Stabrite

Approximately $8 \mu \mathrm{m}$

$0.5^{\prime \prime}$

1000 feet

$10 \%$

To produce this superconductor, Fermilab furnished for each extrusion a three-piece 10" extrusion can, $2400 \mathrm{Mb} 46.5 \% \mathrm{Ti}$ .126 " diameter rods, and 2400 PDOF copper tubes with a .132" inside diameter and a . $177^{\prime \prime}$ hexagonal outside diameter. Both the rods and the tubes are 23.69" long. All material was to be accounted for in full, including the components assembled into the extrusion as well as any surplus components and processing scrap. The conductor to be produced using this wire is a flat, Keystoned cable whose characteristics are given below:

$\begin{array}{ll}\text { Style: } & \begin{array}{l}\text { Rutherford Type - } \\ \text { Hollow Cable }\end{array} \\ \text { Number of Strands: } & 23 \\ \text { Dimensions: } & .308^{\prime \prime} \times .054 " \times .046 " \\ \text { Compaction Factor of Cable: } 0.91 \\ \text { Strand Pitch: } & 2.5 " \\ \text { Minimum Performance: } & 5200 \text { A at } 5 \mathrm{~T}, 4.2 \mathrm{~K}\end{array}$

\section{PRODUCTION CONDUCTOR SPECIFICATION}

Magnetic Corporation of America translated the conductor specification laid down by Fermilab for the use of their components into the conductor described in the table below: 


$\begin{array}{ll}\text { Diameter: } & .027^{\prime \prime} \\ \text { No. of Filaments: } & 2046 \\ \text { Cu/SC Ratio: } & 1.8: 1 \\ \text { Twist Pitch: } & 0.5^{\prime \prime} \\ \text { Filament Diameter: } & 8 \mu \mathrm{m}\end{array}$

It was determined that additional filaments, while improving the critical current of the conductor, could not be processed while meeting the minimum $\mathrm{Cu} / \mathrm{SC}$ ratio specification. Therefore no NbTi was used in space equivalent to 61 filaments.

\section{PRODUCTION PROCESS}

After incoming inspection of all Fermilab furnished components, components for a single extrusion are segregated. Prior to cleaning, an effort was made to select all NbTi alloy rods for an extrusion from a single heat so that performance could be traced to heat identification at a later time. Sufficient $\mathrm{NbTi}$ rods and ASTM B170-1 (PDOF) copper tubes for the assembly of the billet including expected rejects were cleaned by acid dip, two water rinses and two acetone rinses prior to being blown dry with nitrogen gas. Clean tubes are stored in a nitrogen atmosphere prior to assembly. The full array of hexagonal tubes for a single extrusion is assembled in a clean room on a flat surface. Upon inspection of the array and approval, the NbTi rods are inserted into the tubes. When the entire array is completed, the cleaned extrusion can is fitted over the array. All spaces between the array and the inside diameter of the extrusion can are filled with segments of hexagonal copper rods. After inspection and photographing of the finished array, the cleaned lid is fitted on the extrusion billet. Both nose and tail are taped to prevent any contamination by moisture or atmosphere prior to welding. Nose and tail are electron beam welded in a special rotating fixture.

On completion of the electron beam welding, the billet is weighed and held during the readying of sufficient billets for an extrusion run.

The extrusions have been preheated by several standard industrial methods and are extruded to a 2.5" diameter rod. The rods are water quenched and cropped prior to drawing on large draw benches. At approximately 1" diameter the rods are coiled and from that point, they are drawn on bull blocks and multi-die machines to twist-size. After twisting, the wire receives a final die pass and is coated with Stabrite. 
Appropriate major and minor heat treatments are given to the conductor during the drawing process.

\section{QUALITY CONTROL PROCEDURE}

Aside from incoming inspection of materials furnished by Fermilab, there are several routine quality control procedures which are followed meticulously in the production of this wire. All NbTi rods are inspected visually and are measured on a sampling basis to determine the final diameter at assembly. The tubes are also measured on a sampling basis to check inside and outside diameters and overall length. Extrusion cans are measured and each component is weighed upon receipt. The fully assembled billet is photographed prior to electron beam welding. Figure 1 shows a typical cross section. A coupon is cut from the center of each rod as extruded to check the post-extrusion cross-sectional pattern. Figure 2 shows a polished coupon from a typical extrusion. Fractography analyses are made on any breaks encountered during the drawing process. A complete inventory is kept of yields at all diameters to deternine where the process can be improved. Final performance data is obtained in a test magnet to determine wire performance at 4,5 , and 6 Tesla. This sampling is done to assure that at least two pieces are tested from each extrusion. The test results obtained on 50 samples are shown in Fig. 3, which shows the spread of the test data at each point. The target performance specification is the bottom of the error band of the 5 Tesla point on Fig. 3 .

\section{CONCLUSION}

It is felt that with the completion of this production run, all learning processes in the full-scale production of this type of conductor are now experienced. The benefits of large volume production using existing production machinery have progressed to the point where the target goals for quantity production costs have been achieved.

\section{ACKNOWLEDGEMENTS}

The authors want to acknowledge the cooperation of Messrs. Heiser and Henderson at Reactive Metals, Inc., Ashtabula, Ohio, where all of the extrusion on this production 
took place. The authors also want to acknowledge the cooperation and scheduling and technical talks with Mr. R. Plant of Phelps Dodge, South and Bayway Streets, Elizabeth, New Jersey, where all the large diameter drawing on this production took place.

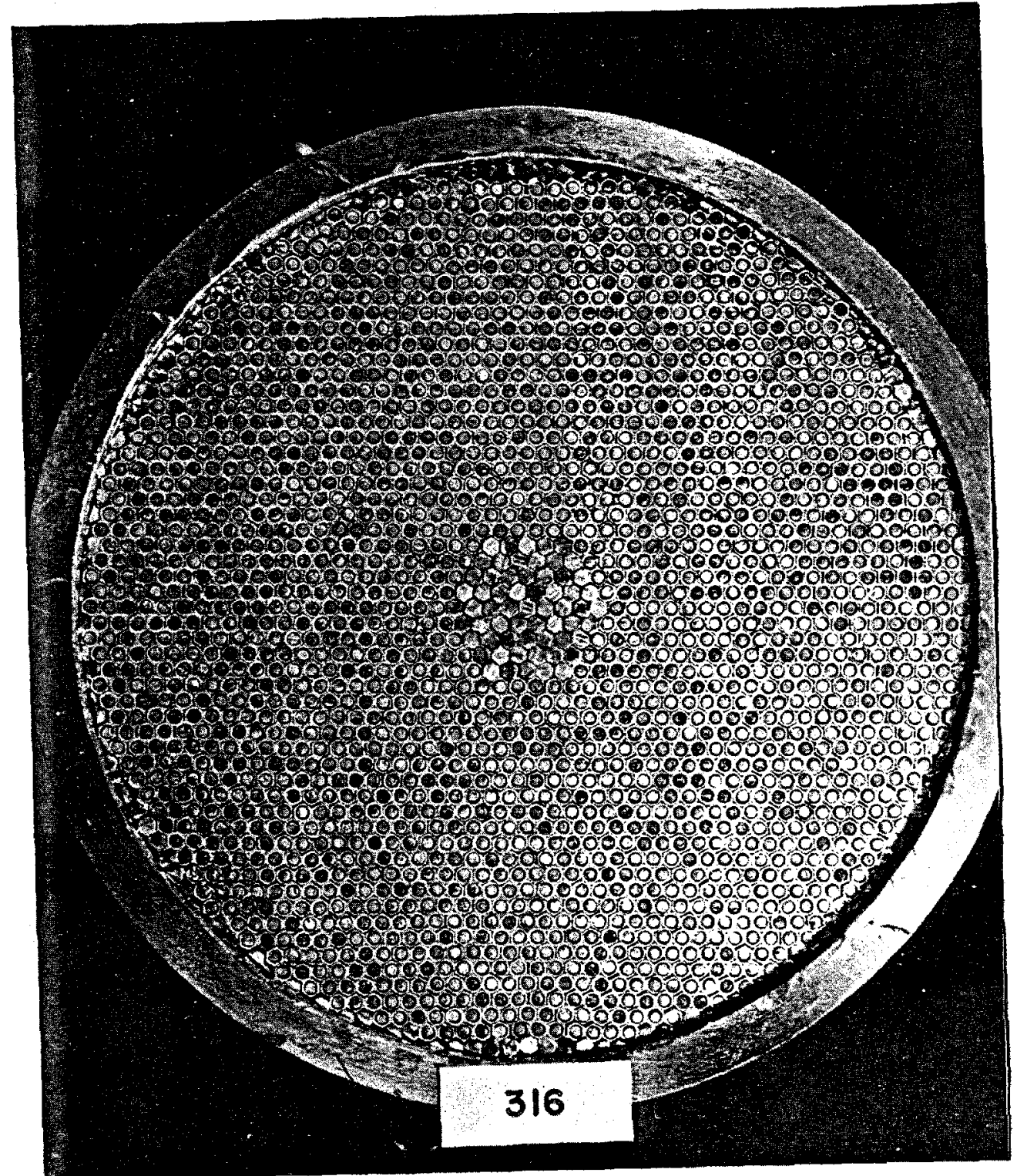

Fig. 1. Typical Extrusion Billet Cross Section Photographed After Assembly of All Components. Billet is Ready for Tail Lid 
Pa
09
0
0
0
0
0
0
0
0
10
$\times$
0
0
0
0
0
0
0
0
0
0
0
0
0
0
0
0
0
0
0
0
0
0
0

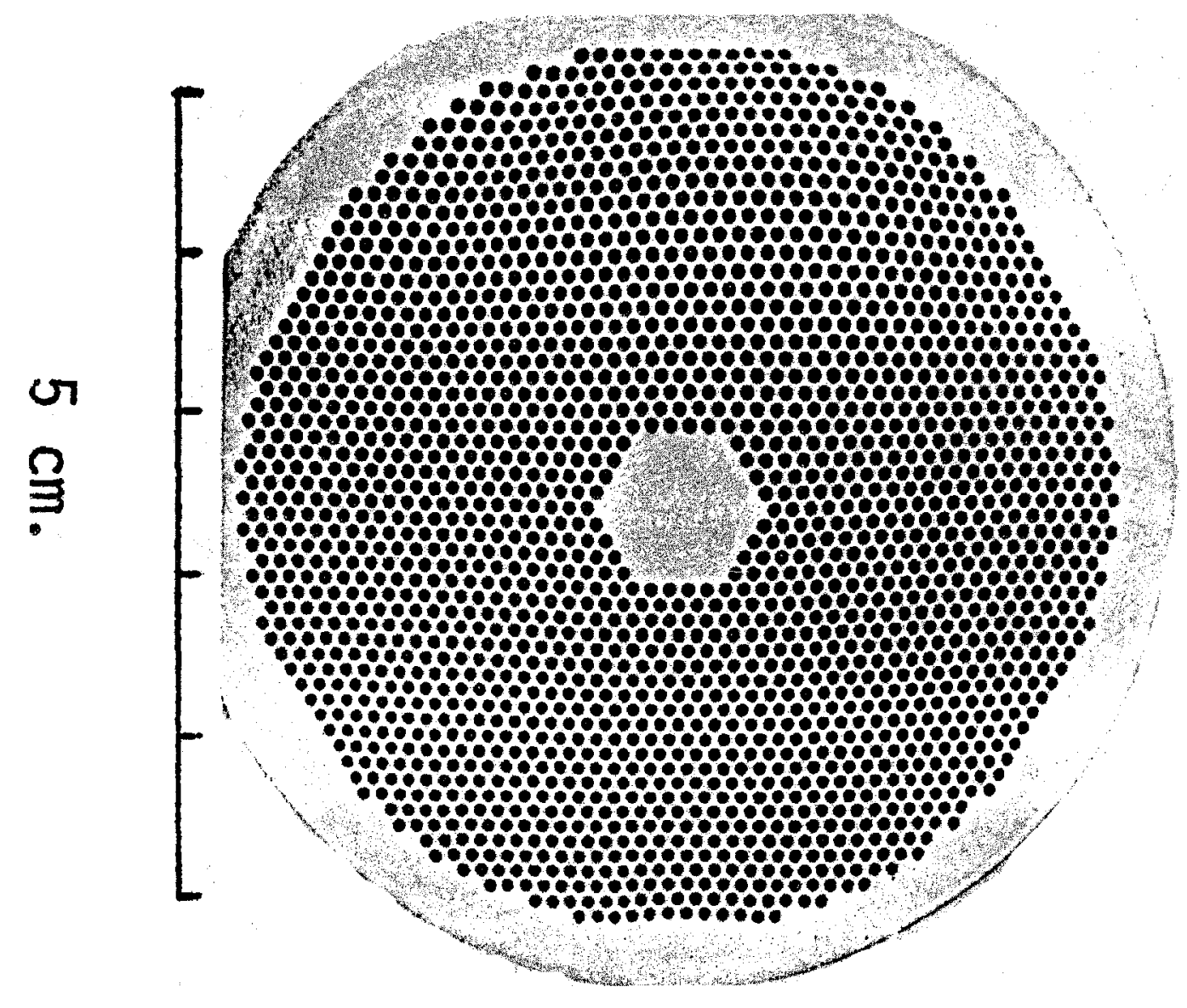




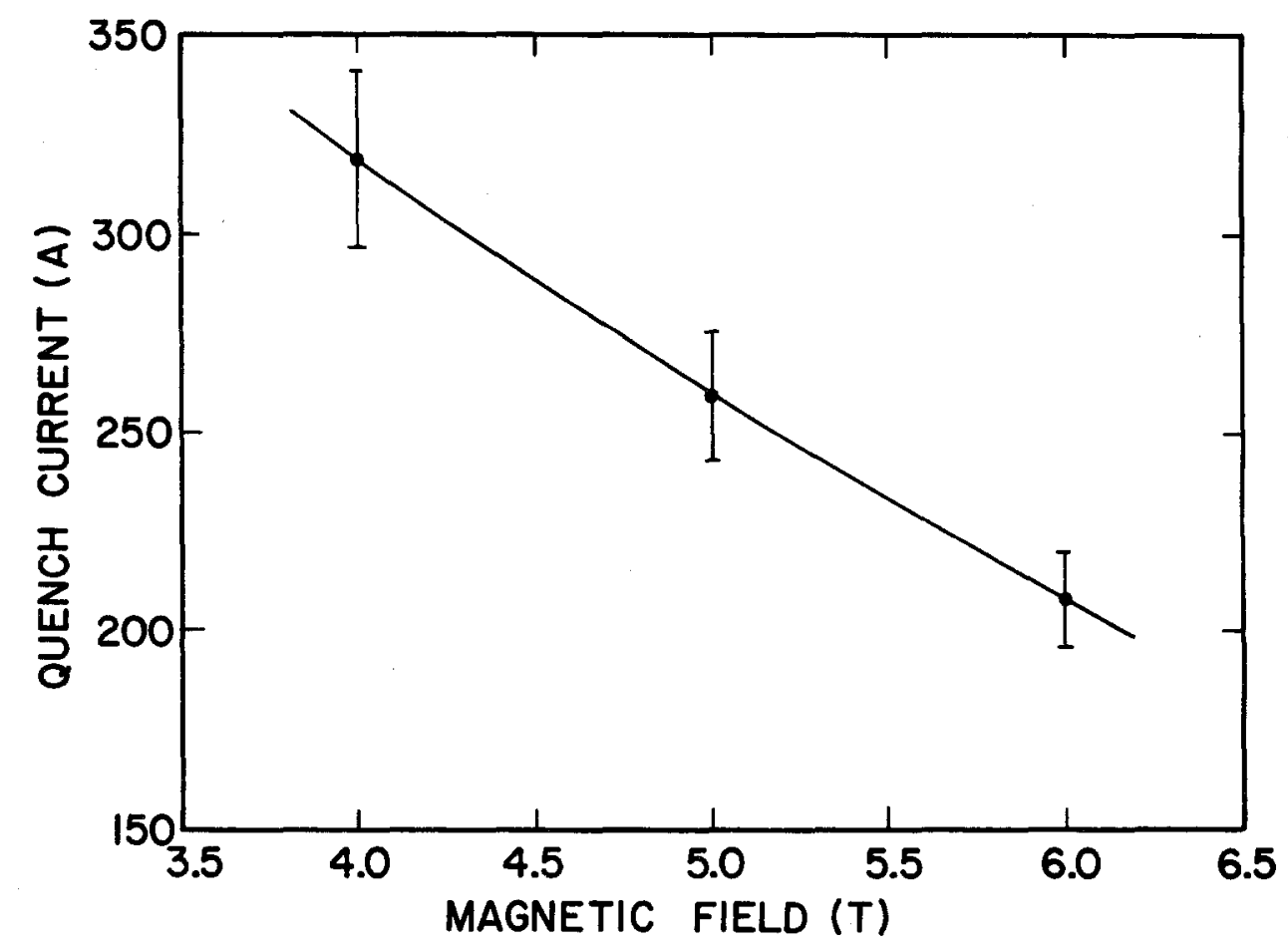

Fig. 3. Short Sample Curve Representing Over 60 Individual Billet Halves 